\title{
REGIME SWITCHING IN THE REAL ESTATE RISK PREMIUM
}

\author{
PATRICK WILSON \\ University of Technology, Sydney \\ JOHN OKUNEV \\ Principal Global Investors, USA \\ TIFFANY HUTCHESON \\ University of Technology, Sydney
}

and

\author{
RALF ZURBRUEGG \\ University of Adelaide
}

\begin{abstract}
While a significant amount of research has been undertaken on the risk premium existing in stock markets, very few studies have evaluated the risk premium in property markets. This paper extends the research on risk premium to the market for securitised property in Australia, Japan, the UK and US. A dividend discount model is applied to model the ex ante risk premium implied from the information contained in the price of securitised property shares. A Markov regime-switching model is then used to determine whether changes in the risk premium lead to changes in market prices for these securities. The results show evidence of a cyclical pattern in the risk premium for the securitised property market that can be used by investors when deciding on the best time to buy or sell in this market.
\end{abstract}

\section{INTRODUCTION}

Although there is an ever-growing literature in studies examining the equity risk premium and the possible factors that drive it, little work, if any, focuses on the risk premium for the securitised real estate industry. This is unfortunate, as portfolio managers are all the more looking towards property as a substantial investment class to diversify risks. However, with little evidence to review the risk premium characteristics that underlie this asset class, it is difficult to ascertain the diversification benefits that can be expected from holding property. Moreover, by examining the time-varying nature of the property risk premium, the question as to whether this premium follows a cyclical pattern (as do most other financial assets) 
can be answered. In addition, the question as to whether it is at all possible to forecast a changing property risk premium can be considered. This paper provides an analysis to bridge this research gap by undertaking an empirical study of the cyclical behaviour of the risk premium inherent within four distinct securitised property markets; these being Australia, Japan, the UK and US.

The first objective of the paper is to model the risk premium implied from information contained in the securitised property price within each market. Using a conventional discounted dividend model, and making certain assumptions on dividend growth, we are able to infer the expected risk premium. A second objective of this paper is to investigate whether a cyclical pattern of risk premia exists in the securitised property market. Reichenstein and Rich (1993) argue that equity risk premiums show signs of a cyclical pattern as changing economic circumstances can provide a signal that a stock is overvalued or undervalued and thereby lead to an ensuing fall or rise in its price. For example, when a stock's risk premium is high relative to its long-term average, the market is concerned about the security of the investment and therefore demands an extra return.

Even though the above study was conducted on the equity market, there is no reason to suppose that risk premia provide signals that are any different in securitised property markets. Certainly there is evidence of cyclical patterns in both physical and securitised property markets. In the US property market, Born and Pyhrr (1994) found that traditional appraisal models that did not explicitly take cyclical fluctuations into account were likely to produce unrealistic valuation estimates, with properties being overvalued or undervalued relative to true market conditions; Irwin and Landa (1987) found cyclical patterns for unleveraged real estate returns with a period of about eight years; Grebler and Burns (1982) found non-residential US construction cycles of about seven years while Wheaton (1987) found office building construction cycles in the US of about ten to twelve years. Research has also produced evidence of cyclical patterns in UK property markets, with Barras and Ferguson (1985) using spectral techniques to identify building cycles ranging from four years to twenty years and Key, Zarkesh, MacGregor and Nanthakumaran (1994) using variations in the rate of all-property returns to find property cycles ranging from three to nine years duration. Finally, Wilson and Okunev (1998) using spectral techniques found evidence of cyclical patterns in real estate return data for the US, the UK and Australia.

Furthermore, it is reasonable to suppose that these cyclical patterns in the property market are being driven by underlying economic forces that are reflected in the market's assessment of the risk of real estate investment. This paper examines the risk premia estimates produced using the discounted dividend model for evidence of regime switches that may be used to indicate when the market has entered a new phase or state of a cycle. Here we follow the approach of Hamilton $(1989,1990)$ who developed a Markov regime switching model to estimate the likelihood of a 
turning point occurring in the series (regime shift), given information about the current regime and past states of the series. Hamilton's work is based on the Markov switching regression models developed by Goldfeld and Quandt (1973). It assumes that the stationary process underlying the series is non-linear, then considers the implications if such a process is subject to underlying shifts in regime. Under this assumption of non-linearity, research has also seen the development of transition autoregressive models popularised by Tong (1990) and Terasvirta and Anderson (1992) (with recent application in the real estate market by Lizieri, Satchell and Dacco (1996) and Lizieri, Satchell, Worzala and Dacco (1998)). Hamilton (1989) applied this technique to the study of post-war business cycles in the United States, where he studied regime shifts from positive to negative growth rates in real GNP. Hamilton found the Markov regime shift approach to be an objective criterion for defining and measuring economic recessions.

So, if fluctuations in risk premia do provide the signals to expected price changes as suggested by Rich and Reichenstein (1993), then risk premia estimates may be viewed as an indicator of anticipated price change in the market. This raises the question as to how we might take advantage of this information. A group of individuals that could profit from using information on a changing risk premium would be traders in the securitised property market. These traders could use indicators of a changing risk premium when making decisions on whether to buy or sell.

The rest of the paper is organised as follows. The next section provides a literature overview of the applications of regime switching models and the risk premium in finance. The third section discusses how the survey data was collected and risk premia estimated for the securitised property markets under review. Section four applies Hamilton's Markov regime switching model to produce probability estimates of likely changes in the market's assessment of the risk of property investment in each of the countries under study. Section five presents a brief conclusion.

\section{LITERATURE REVIEW}

Over the past several years, the application of Markov regime switching models has grown in popularity as a means to effectively deal with modeling financial time series that are affected by time-varying properties. Whether it be for equity, fixed income or derivatives, these models have benefited from the ease by which they can deal with the stochastic properties that underlie most financial and economic data. The ability to also account for market jumps or crashes, along with a long list of features that other more inflexible models cannot deal with also adds to its appeal. This includes issues with mean reversion, asymmetric distributions and the timevarying nature of a distribution of moments. However, there are effectively two main explanations for the reasoning behind noticing these distribution 
characteristics within financial data, which also provides a fundamental understanding as to the practicality of using Markov regime switching models.

The first reason is related to the economic relationship behind financial market movements - that being the business cycle. Some examples of previous studies that have shown this relationship include Cecchetti, Lam and Schaller (1999) who show how dividend payments affect stock return distributions due to changes in economic growth. Hamilton and Lin (1996) also report that economic recessions are a main factor in explaining conditionally switching moments of financial distributions. Work by Campbell, Lettau, Malkiel and Xu (2001) and Schwert (1989) have also shown that there is a counter cyclical effect of economic activity upon stock volatility. Recent theoretical research by Ebell (2001) also shows the relationship between the business cycle and return distributions.

The second explanation lies in the non-linear behavior of exchange trading. Speculative trading is common among financial markets and this can lead to fads and bubbles. Research by Flood and Hodrick (1990) indicates this may suggest evidence of mis-specified fundamentals within financial prices. However, with the application of Markov regime-switching models, studies by Funk, Hall and Sola (1994), Hamilton (1989) and van Norden and Schaller (1999) show that this type of behavior can easily be modeled. Although mainly used to investigate equity markets, the application of Markov models to account for speculative regime shifts is suitable for most financial markets. Dewachter (2001), for example, applied it when examining foreign exchange trading.

The actual methodology utilised to incorporate Markov regime switching models is quite varied. The primary study dates back to Hamilton's (1989) work on simple mean switching, which has led to a number of extensions. These include Turner, Startz and Nelson's (1989) model which allows for variations in both the first and second moments of a distribution between regimes, and Hamilton and Susmel (1994) who examines a conditional heteroscedastic Markov regime switching model. There is now a wide range of alternative models which deal with varying distribution dynamics and asymmetries ${ }^{1}$.

In regards to examining the risk premium, there have been numerous studies in this area on equities, and also what factors are important in explaining the equity risk premium. Papers by Copeland (1982), Fama and French (1988), Finnerty and Leistikow (1993), Reichenstein and Rich (1993), Kairys (1993) and Boudoukh, Richardson and Smith (1993) have all adopted different approaches in attempting to study this risk premium.

\footnotetext{
${ }^{1}$ Some recent examples include Ang and Bekaert (2002), Ang and Chen (2002) and Chauvet and Potter (2000), among others.
} 
Copeland (1982) models ex post holding period returns as composed of an ex ante expected return plus a component of unanticipated return, which may be negative or positive depending on whether investors under or over-estimate expected returns. Using annual observations on Standard and Poor (S\&P) composite stock index and corporate bond index for the period 1926-1978, he concludes that the holding period return spread overestimated the true market risk premium. Fama and French (1988) on the other hand examined the relationship between dividend yields and expected returns and concluded that the risk premium tends to revert slowly to its mean, with reversion often taking a few years. However, Finnerty and Leistikow (1993) model ex post risk premium of various asset classes as a mean reverting process, and find that the risk premium is mean reverting for some asset classes towards a time dependent long term mean for the period 1926-1989. Their model failed to detect mean reversion in the equity risk premium. Finnerty and Leistikow's (1993) conclusions have, however, been questioned by Ibbotson and Lummer (1994) on the grounds that they are able to identify several weaknesses in the empirical analysis undertaken by the study. Their criticisms being primarily focused on the original paper having incorrectly subtracted out the inflation effect from a series that was questionably deflated already, leaving a noticeable decline in real premiums over the course of the sample period used by Finnerty and Leistikow.

Reichenstein and Rich (1993) adopt an ex ante approach and model the long horizon S\&P stock returns in terms of the earnings price ratio, dividend yield and a forecasted risk premium. Their results are similar to those of Fama and French (1988) and Campbell and Shiller (1988) in terms of improved explanatory power with longer-term investment horizons. Their study focuses on a more recent time frame of 1968-1990 and shows that risk premiums based on forecasts instead of historical data, provides more consistent predictions of stock returns than either dividend yield or earnings price ratio.

\section{DATA DESCRIPTION AND METHODOLOGY FOR MODELLING THE RISK PREMIUM}

The analysis utilises securitised property price indices across several countries. There is conflicting evidence as to whether such securitised real estate indices reflect stock market behaviour or are a leading indicator of direct property market behaviour. For instance Ambrose, Ancel and Griffiths (1992) employing a rescaled range analysis found that Mortgage and Equity Real Estate Investment Trusts (REITs) in the US displayed similar return generating characteristics to the stock market and they concluded that securitised real estate and stock markets might be somehow related. Gyourko and Keim (1992) regress Equity REIT returns against returns on the S\&P 500 and find that the S\&P 500 returns have significant explanatory power in predicting Equity REIT returns. Myer and Webb (1993) find that the returns on Equity REITS appear to be much like the returns on common stock. Using linear cointegration techniques, Okunev and Wilson (1997) find no 
evidence of cointegration between real estate and stock markets, although this result is reversed using non-linear techniques. Later, using linear cointegration techniques incorporating structural break tests, Wilson, Okunev and Webb (1998) do not find evidence to support cointegration between securitised real estate and stock markets. In addition, using fractional integration techniques, Wilson and Okunev (1999) find no evidence of long run co-memory between real estate and stock markets in the US or the UK, although the non-linear causality tests employed by Okunev, Wilson and Zurbruegg (2000) provide evidence of causality running from stock markets to real estate markets. While it might be reasonable to expect short run common cycles to exist between securitised real estate and stock markets, there is no reason to believe that such commonality will hold over the long run as securitised real estate may be expected to be ultimately driven by its underlying physical asset.

Furthermore, there have been several recent studies particularly highlighting the risk-return tradeoffs inherent within securitised real estate stocks. This includes work by Ling and Naranjo (2002), showing significant differences in risk and returns between markets, although a worldwide driving factor is also dominant in these markets. Kallberg, Liu and Pasquariello (2002) also show, using a regimeswitching model, that risks and returns altered during the 1997 financial crisis for relationships between Asian equity and real estate markets. Other work, which indirectly examine the property risk premium include Bond, Karolyi and Sanders (2003), Chen and Peiser (1999) and Ling and Naranjo (1998) among others.

Table 1: Annualised monthly returns (\%) (RE) - domestic currency

\begin{tabular}{|l|r|r|r|r|r|r|r|r|}
\hline \multicolumn{10}{|c|}{ Monthly Price Index (PI) - Domestic Currency } \\
\hline & AUSTRE & \multicolumn{1}{c|}{ USRE } & \multicolumn{1}{|c|}{ JAPRE } & \multicolumn{1}{c|}{ UKRE } & AUSTPI & \multicolumn{1}{c|}{ USPI } & \multicolumn{1}{l|}{ JAPPI } & \multicolumn{1}{c|}{ UKPI } \\
\hline Mean & 17.41 & 10.99 & 6.82 & 12.02 & 493.14 & 123.22 & 269.48 & 337.51 \\
\hline Median & 15.21 & 10.98 & 4.08 & 16.51 & 448.73 & 123.18 & 232.16 & 351.80 \\
\hline Max & 210.69 & 131.64 & 644.90 & 192.26 & 998.93 & 163.31 & 718.46 & 629.00 \\
\hline Min & -451.31 & -171.36 & -348.79 & -338.48 & 100.00 & 77.09 & 87.49 & 100.00 \\
\hline Std.Dev & 61.54 & 42.56 & 107.55 & 69.44 & 274.28 & 20.15 & 145.92 & 141.52 \\
\hline Skew & -1.26 & -0.28 & 0.82 & -0.65 & 0.42 & 0.14 & 0.99 & 0.04 \\
\hline Kurtosis & 14.47 & 4.73 & 7.47 & 5.11 & 2.02 & 2.10 & 3.31 & 1.86 \\
\hline
\end{tabular}

Due to differences in data availability across countries, we calculate all risk premia estimates from January 1980 through to mid- $2003^{2}$. Securitised property prices are represented by monthly index measures of real estate trusts that trade on a stock exchange. For the United States, the monthly ALLREITS series is used, while for the United Kingdom, Australia and Japan monthly real estate series developed by Datastream International are used ${ }^{3}$. Risk premia estimates are developed in both

\footnotetext{
${ }^{2}$ Data was generally available from the early seventies. However data prior to 1980 was used for model initiation and 'windowing' as described later.

${ }^{3}$ We accept that the Datastream series is not as good in quality as the series available from NAREIT, but
} 
local currencies and US dollars with base periods set to January 1980. Table 1 provides descriptive statistics on annualised monthly total returns and monthly price indices (all in domestic currencies) from 1980. Here we see that the best performing property market over this period was the Australian, while the Japanese market was the worst performing. The Japanese property market was also the most risky (as measured by the standard deviation), while the least risky market was the United States.

To estimate the risk premium associated with investing in securitised property, we make the initial assumption that shares in securitised property trade in the market place in much the same manner as common stock. It is well documented that the share price for common stock represents the discounted value of the expected future dividend stream. Using this definition, and under our assumption of similarity, the price for securitised property can be represented by:

$P(t)=\sum_{i=1}^{n} \frac{D \times(t+i)}{(1+k)^{i}}+\frac{P(t+n)}{(1+k)^{n}}$

where $P(t)$ is the securitised property price at time t, D $(t)$ is the dividend paid at time $\mathrm{t}$ and $\mathrm{k}$ is the cost of capital (the discount rate) ${ }^{4}$.

To implement part of the analysis, we further assume that the growth in dividends, $g$, from initial investment to the current period will be maintained so the dividend growth rate remains constant (it is not uncommon to assume a constant dividend growth rate; cf. Ball, Lizieri and MacGregor (1998)). Call this our current information model. Consider this for a conventional (perpetuity) discounted dividend model where, if we know the price at time $\mathrm{t}$ and under our dividend growth assumptions above, the implied discount rate is easily extracted:

$$
\begin{aligned}
& P(t)=\frac{D_{0} \times(1+g)}{(k-g)} \\
& k=D_{0} \times \frac{(1+g)}{P(t)}+g
\end{aligned}
$$

The implied risk premium, IRP, is obtained by subtracting the risk free interest rate, $\mathrm{r}_{\mathrm{f}}$, from the implied discount rate. In this paper, the 10-year government bond rate was used as the risk-free interest rate as this was the only common long government bond available across all markets.

these are used in the absence of other suitable data series.

${ }^{4}$ The dividend reflects the dividend yield on the real estate trusts in the index. 


$$
I R P=k-r_{f}
$$

Figure 1 displays the implied discount rates for securitised property in the United States if investors use available information on the growth in dividends from initial investment to the current period. Under the model assumptions, market movements will generate changes in the implied discount rate (and risk premium). Figure 1 also displays the US government 10-year bond rate. Here it can be seen that, apart from a five year period in the early 1980s, the discount rate is mostly above the long term bond rate, which implies that the risk premium in US securitised property market was mostly positive. A similar relationship between the implied discount rate for securitised property and government bond rate was found to exist in United Kingdom, Australia and Japan over the same sample period.

Figure 1: US Implied Discount Rate (IDR)

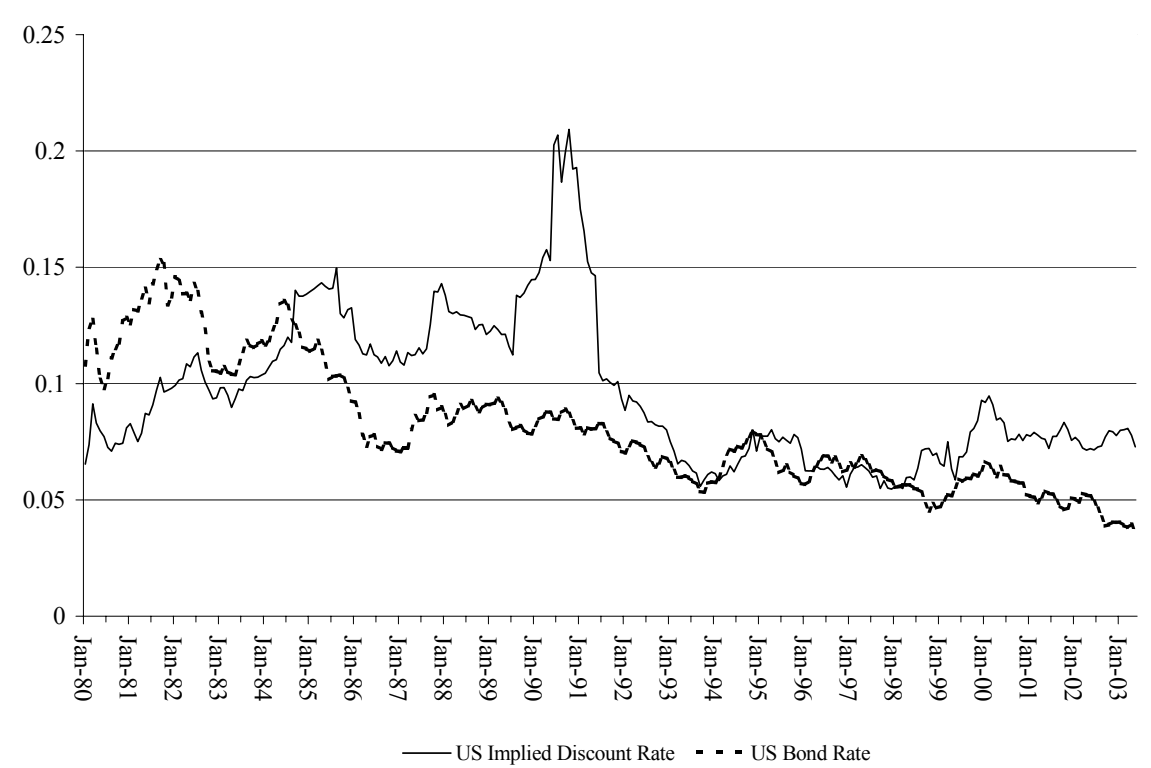

The risk premia estimates for each of the study countries through the eighties and nineties are presented in Figures 2 through to 5. These estimates are presented both in terms of their domestic currency value to better reflect local investor response to local economic factors, and their US dollar value to reflect possible international response to various domestic economic conditions. While the risk premia estimates for the US, UK and Australia exhibit a fair degree of volatility, Japan's risk premia estimates in Figure 4 are of a lower value and less volatile. This may be a reflection of the generally more stable economic conditions in Japan throughout the eighties, 
with the risk premia rising throughout the nineties reflecting the prolonged recession.

Figure 2: Risk premia estimates denominated in local currency

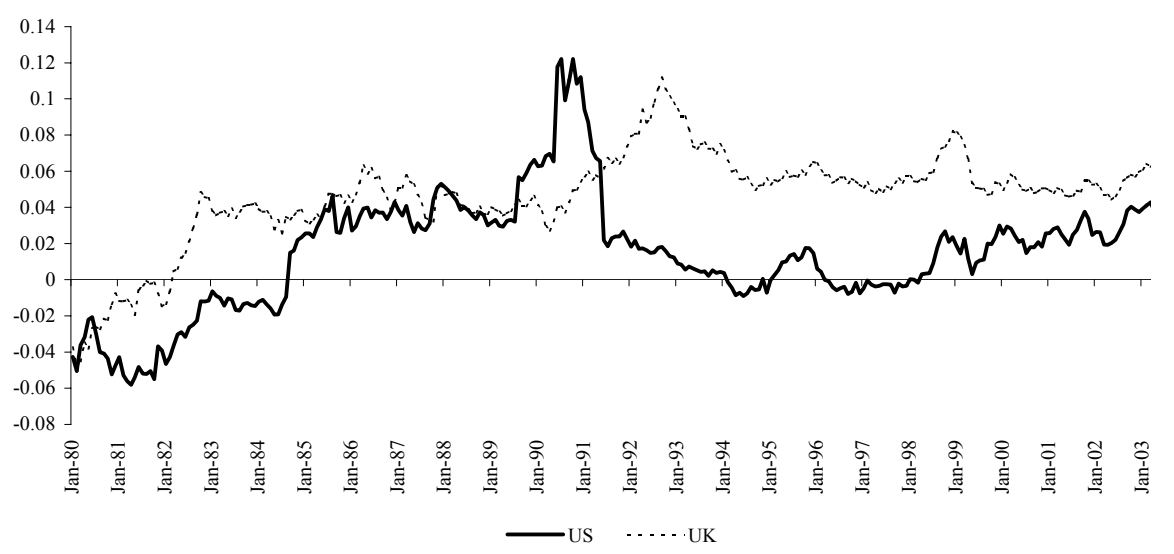

Figure 3: Risk premia estimates denominated in USD

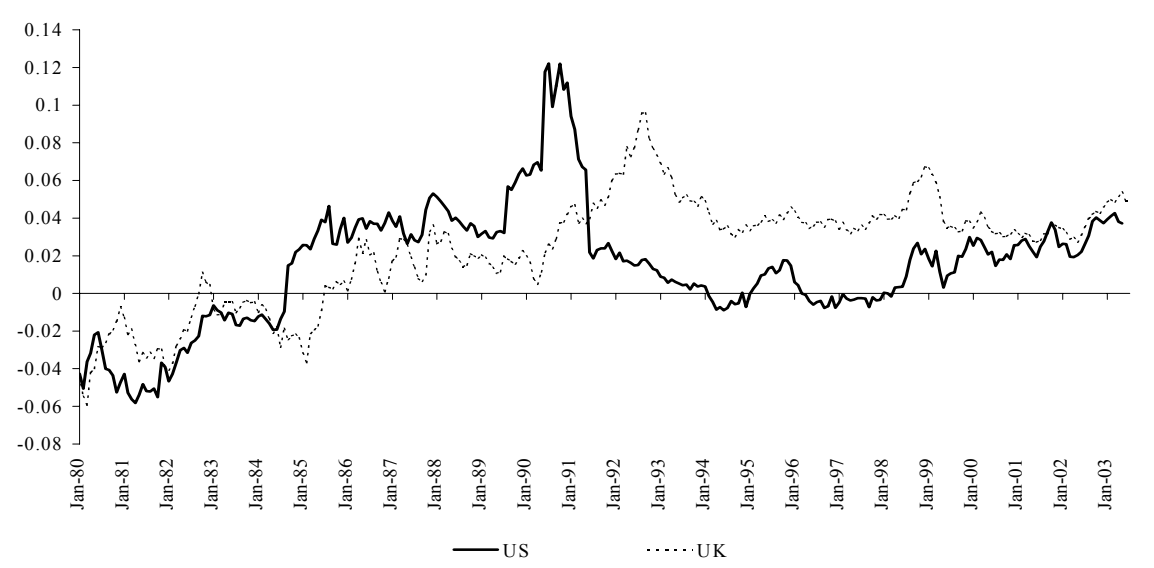

Comparing the US with the UK, both the exchange adjusted and domestic currency risk premia estimates suggest there were possible arbitrage opportunities for investors in securitised property over the study period. This is because low risk premia estimates in one market compared with the other imply that investors in this market believe property may be overpriced relative to the way investors in the other 
market view property in that market. Of course, currency risk is an important consideration for international investors and this aspect has been considered extensively by Ziobrowski and Curcio (1991), Ziobrowski and Boyd (1991) and Ziobrowski and Ziobrowski (1993). This series of papers discuss various means of hedging the currency risk in relation to property investments such as leverage, call options and currency swaps.

\section{Figure 4: Risk premia estimates denominated in local currency}

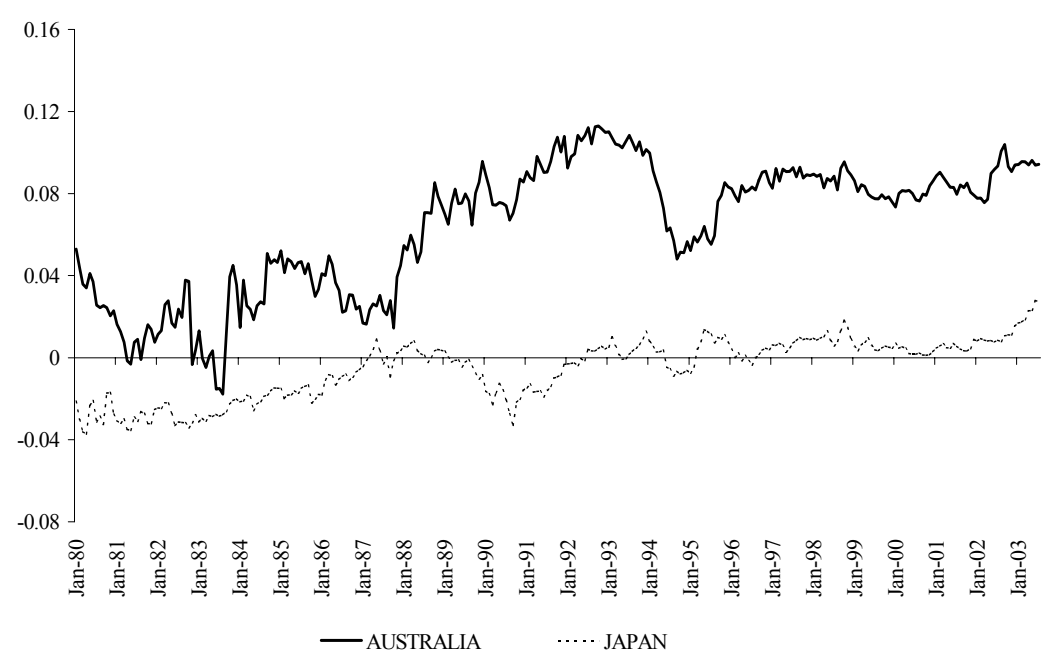

Figure 5: Risk premia estimates denominated in USD

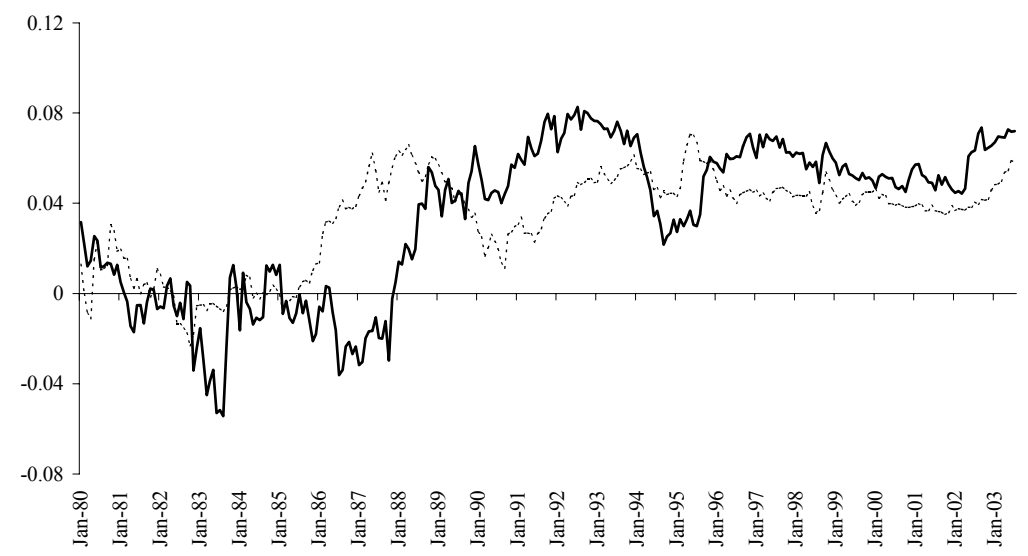

Pacific Rim Property Research Journal, Vol 10, No 2 


\section{REGIME SWITCHING METHODOLOGY}

In the current context, a regime refers to a particular state or phase in which a time series may find itself. For instance, if we are studying risk premia estimates over time, we might refer to the time series as being in a rising phase or a falling phase. That is, we might dichotomise the time series and suggest that there are only two regimes for risk premia - either high or low. In any such analysis, we might introduce several other regimes. For instance, we might introduce two further regimes into rising or falling, depending on whether the change was proceeding at an increasing or decreasing rate. Changes in regime are often handled by the introduction of dummy variables into an autoregressive (or other) model so that the level of the modelled series changes according to whether certain conditions are in effect or not. For example, in the Australian property market, the abolition of negative gearing as an allowable taxation deduction had a marked and dramatic effect on property investment in Australia, with property investment significantly declining after the abolition and significantly increasing after it was reintroduced. The temporary introduction by the Australian government of a first homeowners grant in the seventies and again in July 2000 had a similar impact on property prices. One of the difficulties with the dummy variable approach is that, if we wish to forecast the series for $n$-periods ahead, we have no knowledge as to whether the level of the series will change during our forecast period; that is we have no knowledge of which process is likely to best describe the data.

As a means of dealing with this problem, Hamilton $(1989,1990)$ postulated the change in regime should itself be viewed as a random variable. In that case, a complete time series model would include a description of the probability law governing the change from one regime to the next. Hamilton $(1989,1990)$ further postulated that a Markov process provided a means of describing such probability laws. A Markov process (or chain) is a stochastic process in which the probabilities associated with the outcomes at any stage of the process depend only on the outcomes of the preceding stage. Such a process can be explained as follows. Suppose a history of securitised property price movements suggests the following pattern. If the average price in a given month is higher than the previous month, then the probability that the following month's average price will be higher, unchanged or lower is $0.2,0.3$ and 0.5 respectively. If the average price is unchanged from the previous month, then the probability that the average in the following month closes higher, unchanged or lower is $0.5,0.2$ and 0.3 respectively. Finally, if the average in a given month is lower than the previous month, then the probability that the average in the following month closes higher, unchanged or lower is $0.4,0.4$ and 0.2 respectively. These are the transitional probabilities in moving from one state (e.g. higher) to another state (e.g. lower). This information can be summarised in the tree diagram in Figure 6. 
Figure 6: Tree diagram for Markov process

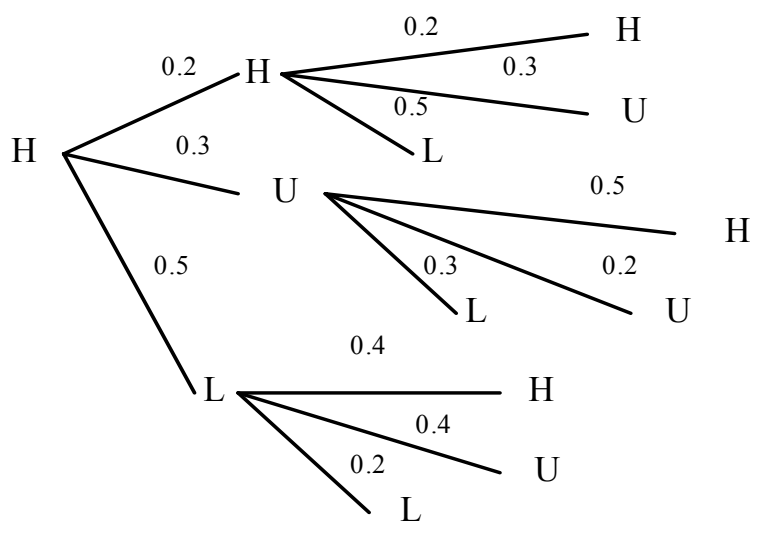

We can estimate the probability of the average price in the next period being higher given the probability of being in the current state (considering previous possible states) as:

$$
\mathrm{P}(\mathrm{H} \mid \mathrm{H}, \mathrm{H})+\mathrm{P}(\mathrm{H} \mid \mathrm{U}, \mathrm{H})+\mathrm{P}(\mathrm{H} \mid \mathrm{L}, \mathrm{H})=0.04+0.15+0.2=0.39
$$

We can do this for each regime or state, hence we can estimate the probability of switching from one regime to another. The transitional probability matrix is given as:

\begin{tabular}{c|ccccc}
$\begin{array}{c}\text { Current } \\
\text { State }\end{array}$ & \multicolumn{5}{c}{ Next State } \\
\hline & State 1 & State 2 & State 3 & $\ldots$ & State n \\
\hline State 1 & $\mathrm{b}_{11}$ & $\mathrm{~b}_{12}$ & $\mathrm{~b}_{13}$ & $\ldots$ & $\mathrm{b}_{1 \mathrm{n}}$ \\
State 2 & $\mathrm{b}_{21}$ & $\mathrm{~b}_{22}$ & $\mathrm{~b}_{23}$ & $\ldots$ & $\mathrm{b}_{2 \mathrm{n}}$ \\
State 3 & $\mathrm{b}_{31}$ & $\mathrm{~b}_{32}$ & $\mathrm{~b}_{33}$ & $\ldots$ & $\mathrm{b}_{3 \mathrm{n}}$ \\
$\ldots$ & $\ldots$ & $\ldots$ & $\ldots$ & $\ldots$ & $\ldots$ \\
State n & $\mathrm{b}_{\mathrm{n} 1}$ & $\mathrm{~b}_{\mathrm{n} 2}$ & $\mathrm{~b}_{\mathrm{n} 3}$ & $\ldots$ & $\mathrm{b}_{\mathrm{nn}}$ \\
\hline
\end{tabular}

where each cell, $b_{i j}$, represents the transitional probability that state $i$ will be followed by state $\mathrm{j}$. 
For instance, in the example from earlier, the transitional probability matrix is:

\begin{tabular}{c|ccc} 
Current State & \multicolumn{3}{c}{ Next State } \\
\hline & State 1 & State 2 & State 3 \\
\hline State 1 & 0.2 & 0.3 & 0.5 \\
State 2 & 0.5 & 0.2 & 0.3 \\
State 3 & 0.4 & 0.4 & 0.2 \\
& & & \\
\hline
\end{tabular}

Hamilton (1994) shows that the m-period ahead transition probabilities for a Markov chain may be calculated by multiplying the transition probability matrix by itself $m$ times.

\section{IDENTIFYING SWITCHES OF REGIME IN RISK PREMIA ESTIMATES}

To initiate model testing on US real GNP, Hamilton arbitrarily chose an AR(4) model as his representation of the unobservable series $\left(z_{t}\right)$. In our analysis, we chose the most parsimonious AR(r) model of the observed series $\left(y_{t}\right)$ to provide initial autoregressive parameter estimates of the unobserved $\mathrm{z}_{\mathrm{t}}$ series, subject to the constraint as specified by Hamilton that $\mathrm{r} \geq 2$.

Table 2: Markov process switching parameter estimates

\begin{tabular}{|c|c|c|c|c|}
\hline Parameter $^{*}$ & United States & $\begin{array}{c}\text { United } \\
\text { Kingdom }\end{array}$ & Japan & Australia \\
\hline $\mathrm{a}_{\mathrm{o}}$ & $0.41(0.49)$ & $0.48(0.33)$ & $0.06(0.56)$ & $0.21(0.4)$ \\
$\mathrm{a}_{1}$ & $1.72(0.50)$ & $1.09(0.33)$ & $0.88(0.54)$ & $1.91(0.41)$ \\
$\lambda_{1}$ & $0.91(0.04)$ & $1.42(0.05)$ & $1.05(0.06)$ & $0.93(0.06)$ \\
$\lambda_{2}$ & $0.27(0.06)$ & $-0.47(0.05)$ & $-0.09(0.06)$ & $0.007(0.06)$ \\
$\lambda_{3}$ & $-0.21(0.04)$ & na & na & na \\
\hline
\end{tabular}

* Standard error in brackets

Since computation times are quite substantial, we chose to limit the number of regimes to the simplest two-regime model where we refer to the risk premia regimes as rising or falling. Tables 2,3 and 4 contain information on the model specification, durations for the rising risk premia regime and transition probabilities. Table 2 contains the maximum likelihood estimates for parameters in the Markov switching model used for the risk premia estimates in each country under study, Table 3 has the transition probability matrices for regime switches in each country and Table 4 holds the estimated duration and occurrence for the rising risk premia regime along with the inferred probability (average) of being in that regime. Figures 8, 10 and 12 present a visual impression of the inferred probability 
of a regime switch (predictions based on the underlying AR model). Overlayed on each inferred probability series is the estimated risk premia series in levels ${ }^{5}$.

Table 3: Transitional probability matrices

\begin{tabular}{|c|c|c|c|c|c|}
\hline US & Reg 1 & Reg 2 & UK & Reg 1 & Reg 2 \\
\hline Reg 1 & 0.98 & 0.02 & Reg 1 & 0.93 & 0.07 \\
\hline Reg 2 & 0.18 & 0.82 & Reg 2 & 0.39 & 0.61 \\
\hline AUST & Reg 1 & Reg 2 & JAPAN & Reg 1 & Reg 2 \\
\hline Reg 1 & 0.99 & 0.01 & Reg 1 & 0.70 & 0.30 \\
\hline Reg 2 & 0.28 & 0.72 & Reg 2 & 0.03 & 0.97 \\
\hline
\end{tabular}

Table 4: Approximate durations rising risk premia regime

\begin{tabular}{|c|l|c|c|l|c|}
\hline Country & Duration & Probability & Country & Duration & Probability \\
\hline US & Oct 84-Sept 85 & 0.81 & Aust & Nov 83-Mar 84 & 0.69 \\
& Sept 89-Aug 90 & 0.79 & & Dec 87-Mar 88 & 0.56 \\
& Sep 98-Nov 98 & 0.81 & & Jul 02-Nov 02 & 0.72 \\
UK & May 85-Sep 85 & 0.55 & Japan & July 84 & 0.69 \\
& Jan 88-Feb 88 & 0.57 & & Dec 85-Jan 86 & 0.65 \\
& July 92 & 0.58 & & Nov 87 & 0.56 \\
& Aug 98-Nov 98 & 0.60 & & Mar 90-May 90 & 0.57 \\
\hline
\end{tabular}

Hamilton (1989) suggests that a sensible decision rule on a regime switch might be that a switch has occurred if the probability of being in the current regime based on past information exceeds 0.5. However in the current analysis, so as to maintain a clear distinction on a regime switch, we arbitrarily chose a marginally larger decision rule such that the probability exceeds $0.55^{6}$, and this is reflected in Table 4 above. This appears reasonable in that the weight of econometric evidence is more in favour of such a switch than not. In each of the following figures, the 'zigzag' horizontal line indicates this 'cut-off' probability. The probabilities are measured on the right hand side axis and estimates for risk premia are shown on the left hand side axis.

\footnotetext{
${ }^{5}$ The Markov model was estimated from the standardised risk premia, which were stationary.

${ }^{6}$ From the presentation in the Appendix, and following Hamilton(1989), this would be written as $\mathrm{P}\left[\mathrm{S}_{\mathrm{t}}=\right.$ $\left.0 \mid \mathrm{y}_{\mathrm{t}}, \mathrm{y}_{\mathrm{t}-1} \ldots \mathrm{y}_{-\mathrm{r}+1}\right]>0.55$.
} 
Figure 8: Probability of rising risk premia - US

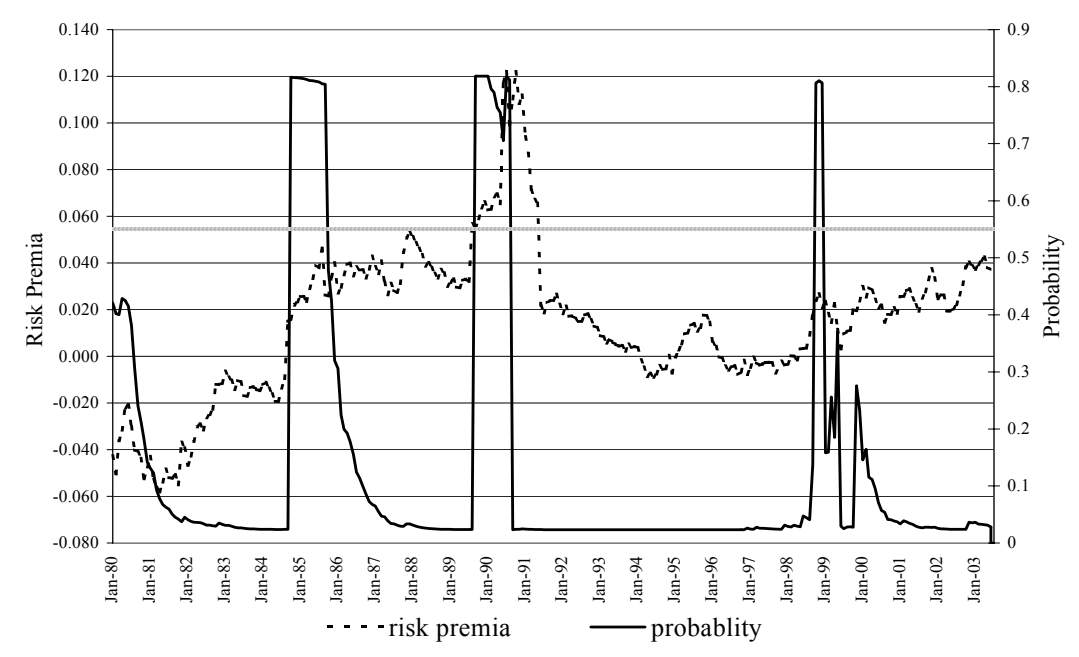

As can be seen in Figure 8 (and Table 4), using this decision rule the Markov process clearly isolated a switch in the market's assessment of risk (to rising risk premia given the previous state as falling) in the US property market on only three occasions over the study period - late 1984, late 1989 and late 1998. A visual inspection of Figure 8 suggests that, in terms of the behaviour of the series, this appears to be correct. How useful was this information in terms of the apparent behaviour of investors in the market? The risk premium measures an investor's aversion to risk. If the risk premium is low, this implies that investors are prepared to take on more risk, and this usually occurs in a rising market. When the risk premium is high, investors require an added premium to invest in risky assets. This usually occurs in falling markets. Behaviour in the marketplace may be more clearly visualised by standardising prices. Here we have standardised the ALLREIT price index using a five-year window ${ }^{7}$. Given the differing estimates of cyclical behaviour in the property market (discussed earlier), a five year window was deemed a reasonable period to permit the dynamics of risk adjustment behaviour on the part of investors to be captured. The standardised index is shown

\footnotetext{
${ }^{7}$ The standardised values were estimated on the basis of:

$$
z=\frac{x_{i}-\mu}{\sigma}
$$
}

where $\mu$ and $\sigma$ are the respective mean and standard deviation for the sixty month 'window' and the $\mathrm{x}_{\mathrm{i}}$ is the given value. The standardised index is a measure of the number of standard deviations of the index price from this mean. 
in Figure 9 and overlayed on this is the probability of a regime switch in risk premia from the previous diagram.

Figure 9: Market behaviour - US

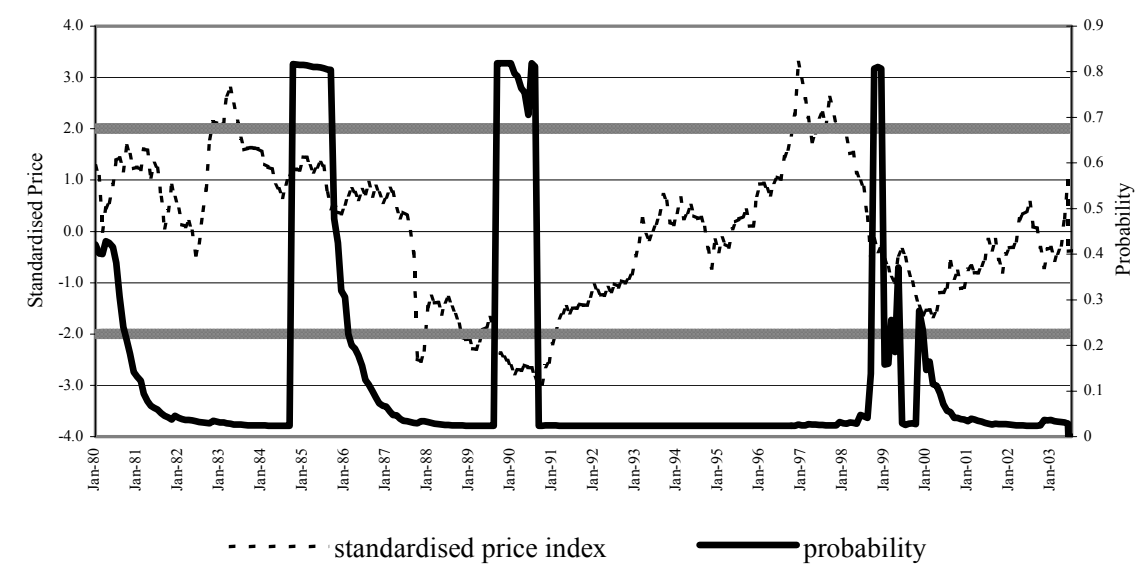

Interestingly, we see that the expected market behaviour is captured at the given periods. As shown in Table 2, the AR(3) model was deemed the most parsimonious (meeting all diagnostic requirements) to capture the Markov switching behaviour for US risk premia, while the AR(2) model was the most parsimonious for the UK, Australian and Japanese risk premia. Prior to each of the indicated switches, the market fell over a period before the Markov model captured this change. The model appears to be useful in isolating recessionary periods in the US property market. The 'heavy chain' horizontal lines above and below the left hand side axis in Figure 9 represent \pm 2 standard deviations from the five-year mean for the standardised market index. A movement of the standardised index outside these bounds conveys additional information about likely market behaviour. In Figure 9, it can be seen that when the index moved outside \pm 2 standard deviations, the market usually changed direction within six months of this movement. To present an overall picture of market behaviour, both the regime switching model and the standardised lines need to be used in combination since the Markov model operates as a (somewhat delayed) confirmatory indicator of what the standardising technique signals.

Figure 10 shows the regime switch risk premia model for the UK where we again show the probability of rising risk premia. The risk premia in the UK appeared to be more volatile than in the US over the same period and this is reflected in many more probability spikes, although only four breached our decision rule criteria. Somewhat surprisingly, the long rise that commenced mid 1990 did not quite reach the decision criteria, although it did about July 1992. 
Figure 10: Probability of rising risk premia - UK

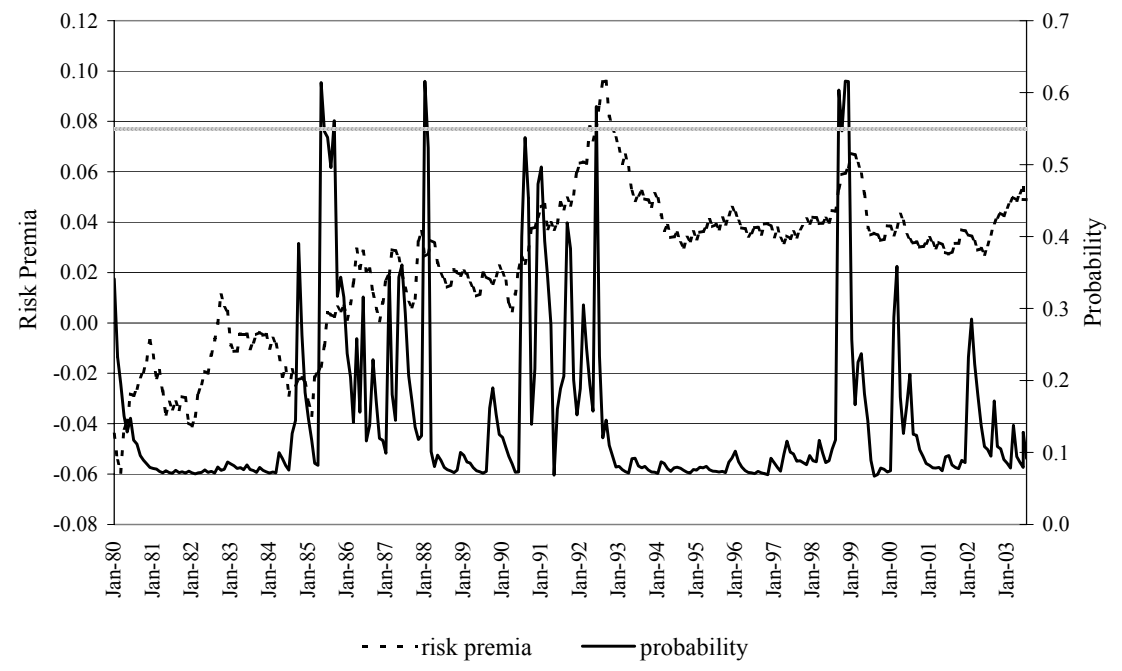

In Figure 11, we superimpose the probability of risk premia rising on a standardised price returns index for the UK property market to ascertain what this tells us about market behavior. The probability of risk premia rising should be indicative of the likelihood that the market will fall. In this regard, the model produced a false alarm about May 1985 in the sense that, while the market fell shortly thereafter, this was minor and short lived. In all other cases, the model correctly identified a market fall, although in many cases the market was actually in the process of falling when a 'likely' fall was identified. More noteworthy is the regularly identified falling market from about January 1989 through the early 1990s.

In Figure 11, we have again inserted the \pm 2 standard deviation boundary lines using a five-year window. As was the case with the US market, when the standardised index moved outside these boundaries, the market changed direction within six to twelve months (and sometimes sooner). In contrast to most instances with the regime-switching model, the standardised boundary model provided a lead-time for likely changes in market behaviour.

The probability of risk premia rising (given the previous state of falling) is shown for the Australian property market in Figure 12. Again, there appeared to be a great deal of uncertainty in this market and this uncertainty is reflected in a number of probability spikes indicating the likelihood of risk premia rising (and the market 
falling). In all, there were four probability spikes that satisfied our decision criteria ${ }^{8}$.

\section{Figure 11: Market behaviour - UK}

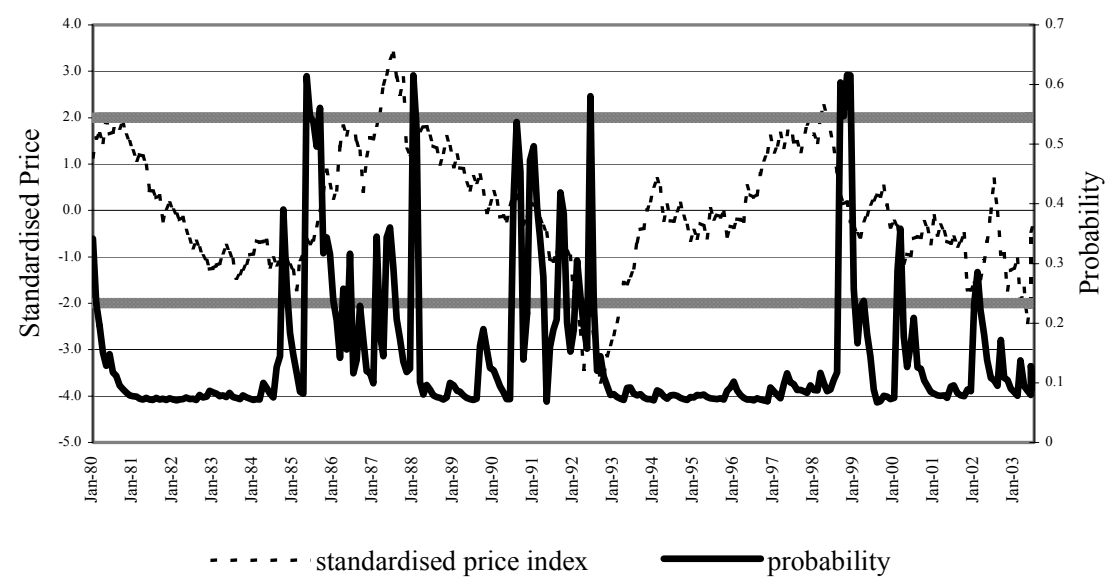

Figure 12: Probability of rising risk premia - Australia

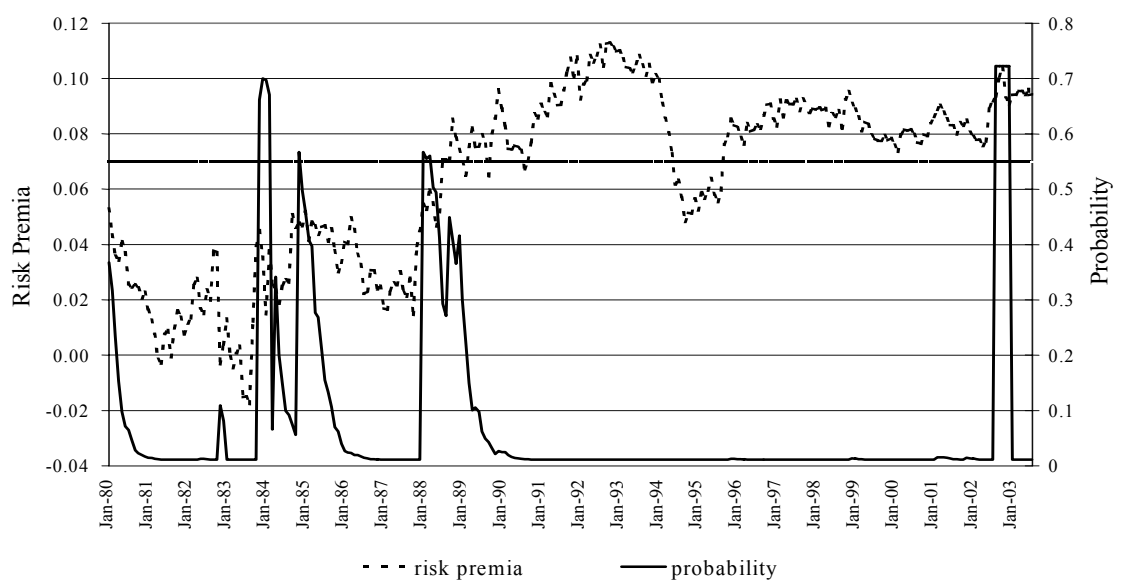

\footnotetext{
${ }^{8}$ It should be noted, again, that the data for Australia, Japan and the UK is from a different source than that for the US. The data for Australia, Japan and the UK comes from indices that are actually constructed by Datastream International.
} 
Figure 13: Market behaviour - Australia

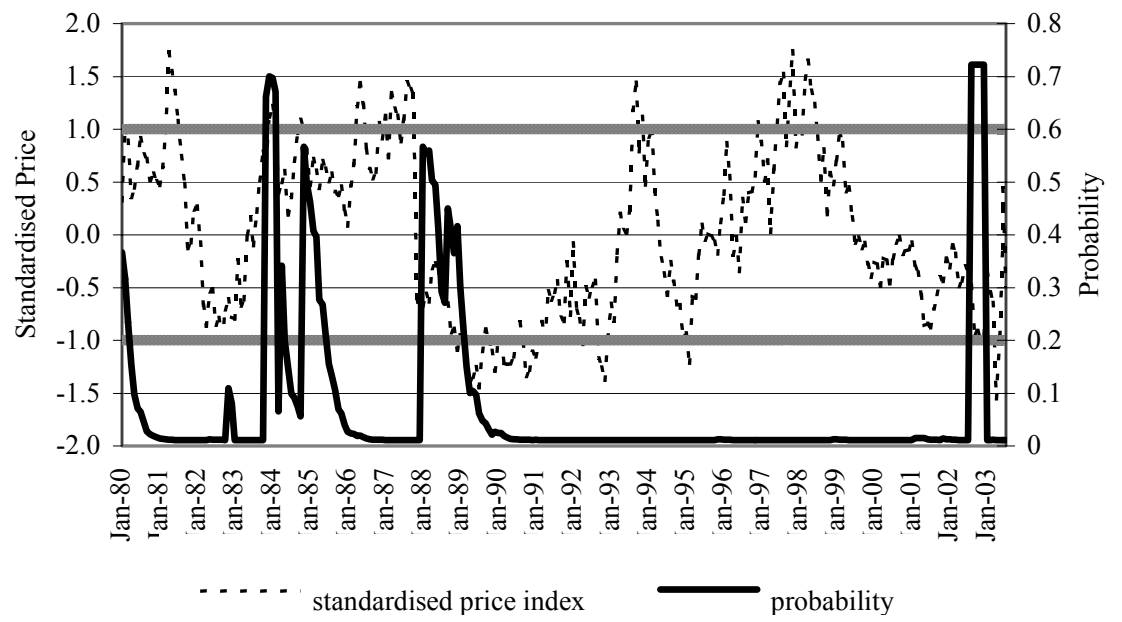

We again asked what this indicated to us regarding behaviour in the property market. Figure 13 superimposes the probability of a regime switch in risk premia on the price returns index (standardised using a five year window) for the Australian securitised property market. Here we see that on each occasion when the probability spikes indicated a high probability of risk premia rising the market was either in the process of falling or fell shortly thereafter. Also in Figure 13, we have superimposed the \pm 1 standard deviation boundary lines (as the market did not move outside the two deviation boundary). As was the case with the US and the UK, when the standardised index moved outside the boundary, it signalled that a change in direction was imminent - in Australia's case, this was often within three months.

As shown in Figure 14, the regime-switching model appeared highly sensitive and, on occasion, performed poorly (early 1990) when applied to risk premia in the Japanese securitised property market. Interestingly, however, when the probability of a switch to rising risk premia was superimposed on the standardised price returns index (Figure 15), the model often correctly identified market falls, although usually with a lagged effect and the falls were sometimes small and short lived. When \pm 3 standard deviation boundary lines were superimposed, this usually signalled likely changes in the market, although this procedure performed poorly in the mid-eighties since the market fluctuated above the two standard deviation boundary line for several years. Three standard deviation boundaries were imposed as shown in Figure 15 and these appeared to produce more timely information on likely market behaviour (ie. movement back inside the bounds). 
Figure 14: Probability of rising risk premia - Japan

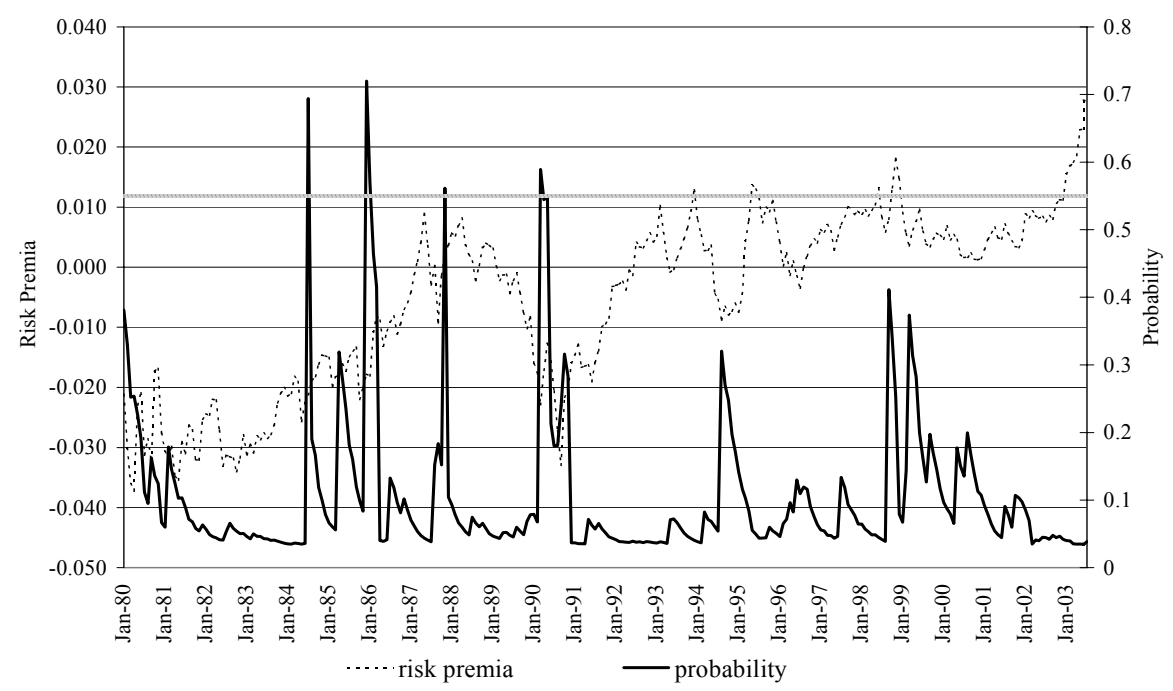

Figure 15: Market behaviour - Japan

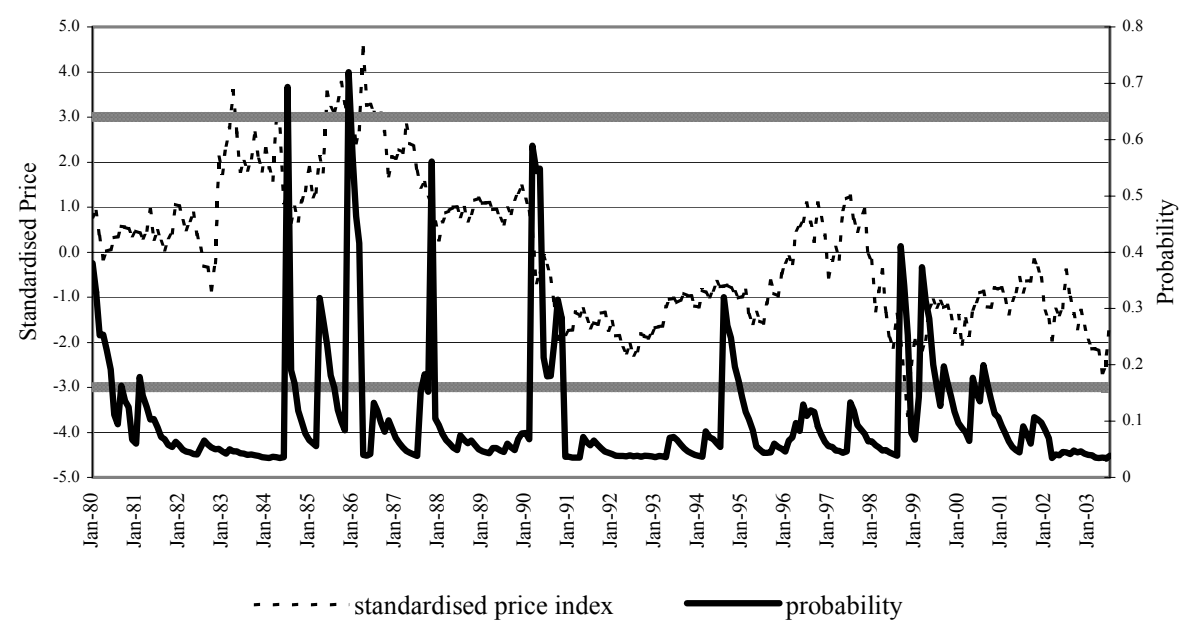

\section{CONCLUSIONS}

This paper had two objectives: to estimate the risk premium associated with investment in securitised property in each of the US, UK, Australian and Japanese markets and to use a Markovian regime switching model in an attempt to discover 
whether our estimates of risk premia provided any signals on changes in market behaviour.

A conventional discounted dividend model was used to extract the discount rate assuming a constant dividend growth rate. The risk premium measures an investor's aversion to risk and variations in the risk premium reflect investors' aggregate belief in likely market movements. If the risk premium is low, this implies that investors are prepared to take on more risk, and this usually occurs in a rising market. When the risk premium is high, investors require an added premium to invest in risky assets. This usually occurs in falling markets. Thus increases in the risk premium are indicative of a decline in the market price of the asset. To ascertain whether fluctuations in risk premia did yield information on market behaviour, a Markov regime switching model was first applied to the standardised risk premium estimates in each country. Using a decision rule whereby a switch in regime was deemed to have occurred if the probability of such a switch exceeded 0.55 (given current and past information), a number of changes in state were isolated. In general, the probability 'spikes' in the Markov model occurred simultaneously with a change in state for the risk premia. The probability model was then superimposed on a standardised pattern of price returns for each country (using a five year 'window'). In a large number of instances across the study countries, this procedure provided signals of either current or likely movements in the market - risk premium rises signalled a decline in the market. Unfortunately some such movements were relatively minor and short-lived, and sometimes incorrect. As a further means of identifying likely market behaviour, $\pm 1, \pm 2$ or \pm 3 standard deviation boundaries were superimposed on the standardised price index for each country. In the case of the US and UK markets, movements outside the two standard deviation boundaries indicated an imminent change in the market. In the case of Australia, a movement outside the one standard deviation boundary indicated a likely change, while in Japan a movement outside the three standard deviation boundary appeared to produce more timely information on market movement.

\section{REFERENCES}

Ambrose, B. W., Ancel, E. and Griffiths, M.D., (1992). The fractal structure of real estate investment returns: the search for evidence of market segmentation and nonlinear dependency. Journal of the American Real Estate and Urban Economics Association, Vol. 20, 23-54.

Ball, M., Lizieri, C. and Macgregor, B. D. (1998). The Economics of Commercial Property Markets. Routledge, London.

Barras, R. and Ferguson, D. (1985). A spectral analysis of building cycles in Britain. Environment and Planning A, Vol.17. 
Bond, S.A., Karolyi, G.A. and Sanders A.B. (2003). International real estate returns: a multifactor, mutlicountry approach. Real Estate Economics, Vol. 31, 481500.

Born, W.L., and Pyhrr, S.A. (1994). Real estate valuation: the effect of market and property cycles. The Journal of Real Estate Research, Vol.9, No.4, 455-486.

Boudouhh, J., Richardson, M. and Smith T. (1993). Is the ex ante risk premium always positive. Journal of Financial Economics, Vol. 34, pp 455-486.

Campbell, J.Y., Lettau, M., Malkiel, B.G. and Xu, Y. Have individual stocks become more volatile? An empirical exploration of idiosyncratic risk. Journal of Finance, 56, 1-43.

Campbell, J. Y., and Shiller, R. J. (1988). Stock prices, earnings and expected dividends. Journal of Finance, Vol. 43, 661-678.

Cecchetti, S.G., Lam P, Mark, N.C. (1990). Mean reversion in equilibrium asset prices. American Economic Review, Vol. 80, 398-418.

Copeland Jr., B.L. (1982) Inflation, interest rates and equity risk premiums. Financial Analysts Journal, Vol. 38, No. 3, 32-43.

Chen, J. and Peiser, R. (1999) The risk and return characteristics of REITs: 19931997. Real Estate Finance, Vol. 16, 61-68.

Dewachter, H. (2001) Can Markov switching models replicate chartist profits in the foreign exchange market? Journal of International Money and Finance, Vol. 20, $25-41$.

Ebell, M.C. (2001) Why are asset returns more volatile during recessions? A theoretical explanation. Study Centre Gerzensee (Working Paper 01).

Fama, E. F., and French, K. R. (1988) Dividend yields and expected stock returns. Journal of Financial Economics, Vol. 22, 3-25.

Finnerty, J., and Leistikow, D. (1993) The behavior of equity and debt risk premiums. Journal of Portfolio Management, Vol. 19, No. 4, 73-84.

Flood, R.P., and Hodrick, R.J. (1990) On testing for speculative bubbles. Journal of Empirical Perspectives, Vol. 4, 85-101. 
Funke, M., Hall, S. and Sola, M. (1994) Rational bubbles during Poland's hyperinflation: Implications and empirical evidence. European Economic Review, Vol. 38, 1257-1276.

Goldfeld, S. M., and Quandt, R. E. (1973) A Markov model for switching regression. Journal of Econometrics, Vol. 1, No. 1, 3-16.

Grebler, L., and Burns, L. S. (1982) Construction cycles in the United States since world war II. Journal of the American Real Estate and Urban Economics Association, Vol.10, No.2.

Gyourko, J., and Keim, D. (1992) What does the stock market tell us about real estate returns? Journal of the American Real Estate and Urban Economics Association. Vol.20.

Hamilton, J.D. (1989) A new approach to the economic analysis of nonstationary time series and the business cycle. Econometrica, Vol. 57, 357-384.

Hamilton, J.D. (1990) Analysis of time series subject to changes in regime. Journal of Econometrics, Vol. 45, No. 1-2, 39-70.

Hamilton, James D. (1994) Time Series Analysis. Princeton University Press, Princeton, New Jersey.

Hamilton, J. D. and Lin, G. (1996) Stock market volatility and the business cycle. Journal of Applied Econometrics, Vol. 11, 573-93.

Hamilton, J. D. and Susmel, R. Autoregressive conditional heteroskedasticity and changes in regime. Journal of Econometrics, Vol. 64, 307-33.

Ibbotson, R. G. and Lummer, S. L. (1994) The behaviour of equity and debt risk premiums: comment. Journal of Portfolio Management, Vol. 20, No. 4, 98-100.

Irwin, S. H. and Landa, D. (1987) Real estate, futures and gold as portfolio assets. Journal of Portfolio Management, Vol.14, No. 1, 29-34.

Kalberg, J., Crocker, H., Pasquariello, P. (2002) Regime shifts in Asian equity and real estate markets. Real Estate Economics, Vol. 30, 263-291.

Kairys, J. (1993) Predicting sign changes in equity risk premiums using commercial paper. Journal of Portfolio Management, Vol. 20, No.1, 41-52. 
Key, T., Zarkesh, F., MacGregor, B. and Nanthakumaran, N. (1994) The Property Cycle. Main Report: Economic Cycles and Property Cycles, IPD for Royal Institution of Chartered Surveyors.

Kim, C. and Nelson, C. R. (1999) State-Space Models with Regime Switching. MIT Press Cambridge.

Krolzig, H. (1997) Markov-Switching Vector Auto Regressions. Springer, London.

Ling, D. and Naranjo, A. (1998) The fundamental determinants of commercial real estate returns. Real Estate Finance, 13-24.

Ling, D. amd Naranjo, A. (2002) Commercial real estate return performance: a cross-country analysis. Journal of Real Estate Finance and Economics, Vol. 24, 119-142.

Lizieri, C. S., Satchell, S. and Dacco, R. (1996) Property company performance and real interest rates: a regime-switching approach. Working Papers in Land Management and Development No.45, University of Reading.

Lizieri, C. S., Satchell, S., Worzala, E. and Dacco, R. (1998) Real interest regimes and real estate performance: a comparison of UK and US markets. Journal of Real Estate Research, Vol.16, No.3, 339-356.

Myer, N. and Webb, J. (1993) Return properties of equity REITs, common stocks and commercial real estate. Journal of Real Estate Research, Vol. 8, No.1, 87-106.

Okunev, J. and Wilson, P.J. (1997) Using non-linear tests to examine integration between real estate and stock markets. Real Estate Economics, Vol. 25, 487-503.

Okunev, J., Wilson, P. J. and Zurbruegg, R. (2000) The causal relationship between real estate and stock markets. The Journal of Real Estate Finance and Economics, Vol. 21, No.3, 251-262.

Rich, S. and Reichenstein (1993) The market risk premium and long term stock returns. Journal of Portfolio Management, Vol. 19, No.4, 63-73.

Schwert, G.W. (1989) Why does stock market volatility change over time? Journal of Empirical Finance, Vol. 5, 131-154.

Terasvirta, T. and Anderson, H. M. (1992) Characterizing nonlinearities in business cycles using smooth transition autoregressive models. Journal of Applied Econometrics, Vol. 7, 119-136. 
Tong, H. (1990) Non-Linear Time Series: A Dynamical System Approach. Oxford University Press, Oxford.

Turner, C., Startz, R. and Nelson, C. (1989) A Markov model of heteroskedasticity, risk and learning in the stock market. Journal of Financial Economics, Vol. 25, 322 .

Van Norden, S. and Schaller, H. (1999) Speculative behavior, regime switching and stock market fundamentals. In P. Rothman (Ed.), Nonlinear time series analysis of Economic and Financial Data, Vol. 1 (321-356). Dordrecht: Kluwer.

West, K. D. (1988) Bubbles, fads and stock price volatility tests: a partial view. Journal of Finance, Vol. 43, 639-656.

Wheaton, W. C. (1987) The cyclical behaviour of the national office market. Journal of the American Real Estate and Urban Economics Association, Vol.15, No.4, 281-299.

Wilson, P. J. and Okunev, J. (1999) Long-term dependencies and long run nonperiodic co-cycles: real estate and stock markets. Journal of Real Estate Research, Vol.18, No.2, 257-278.

Wilson, P.J. and Okunev, J. (1998) Cycles and regime switching models in real estate and financial assets markets. 14th ARES Conference, Monterey, California.

Wilson, P., Okunev, J. and Webb, J. (1998) Step interventions and market integration: tests in the US, UK and Australian property market. Journal of Real Estate Finance and Economics, Vol. 16, No. 1, 91-123.

Ziobrowski, A. J. and Boyd, J.W. (1991) Leverage and foreign investment in US real estate. Journal of Real Estate Research, Vol. 7, 33-58.

Ziobrowski, A. J. and Curcio, R. J. (1991) Diversification benefits of US real estate to foreign investors. Journal of Real Estate Research, Vol. 6, 119-142.

Ziobrowski, A. J. and Ziobrowski, B.J. (1993) Hedging foreign investments in US real estate with currency options. Journal of Real Estate Research, Vol. 8, 27-54. 